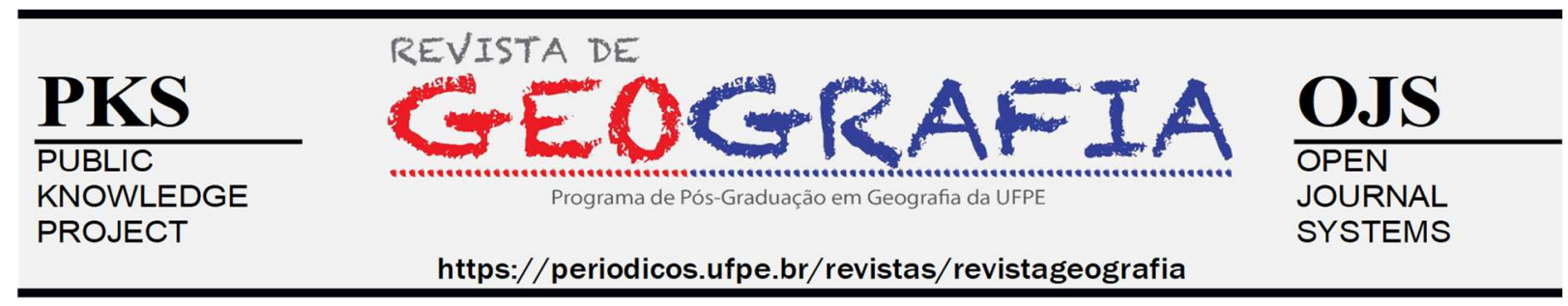

\title{
PERCEPÇÃO AMBIENTAL DOS MORADORES DA BACIA HIDROGRÁFICA DO RIO TAPAIÚNA, NOVA CANAÃ DO NORTE, MATO GROSSO
}

\author{
Luana Rodrigues de Carvalho $^{1}$, Leila Nalis Paiva da Silva Andrade ${ }^{2}$, Celia Alves de Souza ${ }^{3}$ \\ ${ }^{l}$ Graduada e mestre em Geografia pela Universidade do Estado de Mato Grosso. E-mail: \\ luana.carvalho@unemat.br \\ ${ }_{2}^{2}$ Professora adjunta no curso de Geografia na Universidade do Estado de Mato Grosso, Campus de Cáceres. E- \\ mail:leilaandrade@unemat.br \\ ${ }^{3}$ Professora no curso de Geografia e nos Programas de Pós Graduação em Geografia e Ciências Ambientais na \\ Universidade do Estado de Mato Grosso. E-mail: celiaalvesgeo@globo.com
}

Artigo recebido em 10/10/2019 e aceito em 30/05/2020

\begin{abstract}
RESUMO
Nos últimos anos, devido à crescente evidência da degradação ambiental, a questão ambiental ganhou espaço no palco de discussões científicas, sociais e políticas. O ambiente é percebido de formas distintas de acordo com cada indivíduo, sendo justificado pelas diversas construções culturais e sociais. Nesse sentido, o presente trabalho teve como objetivo avaliar a percepção ambiental dos moradores pioneiros da bacia hidrográfica do rio Tapaiúna, em Nova Canaã do Norte, Mato Grosso. O trabalho contou com uma abordagem qualitativa por meio da realização de entrevista semiestruturada com 10 moradores pioneiros da bacia. Identificou-se a percepção ambiental dessas pessoas em relação ao processo de ocupação, a mudança da paisagem, aos tipos de uso e problemas ambientais recorrentes na bacia. Notou-se que os entrevistados possuem afetividade pela bacia ao relatar a importância dos rios e florestas, chegando a comparar o Rio Tapaiúna com o sangue humano devido à preciosidade de suas águas. Além disso, os entrevistados apontaram que a sensibilização e a união de todos seriam capazes de diminuir os impactos negativos na bacia hidrográfica do rio Tapaiúna.
\end{abstract}

Palavras-chave: Uso e ocupação; Água; Rio Teles Pires; Entrevista; Relato de memória.

\section{ENVIRONMENTAL PERCEPTION OF RESIDENTS OF THE TAPAIÚNA RIVER BASIN, NOVA CANÃ̃ DO NORTE, MATO}

\begin{abstract}
In recent years, due to the growing evidence of environmental degradation, the environmental issue has gained prominence at the level of scientific, social and political discussions. The environment is perceived in different ways according to each individual, being justified by the diverse cultural and social constructions. In this sense, this study aimed to assess the environmental perception of pioneer residents of the Tapaiúna River Basin, in Nova Canaã do Norte, in the Brazilian state of Mato Grosso. The work had a qualitative approach through a semistructured interview with 10 pioneer residents of the basin. The environmental perception of these people was identified in relation to the occupation process, changes in the landscape, types of use, and recurrent environmental problems in the basin. It was noted that the interviewees showed an affection for the basin when reporting the importance of rivers and forests, going as far as comparing the Tapaiúna River with human blood due to the preciousness of its waters. Additionally, the interviewees noted that raising awareness and uniting everyone would be able to reduce the negative impacts on the Tapaiúna River Basin.
\end{abstract}

Keywords: Use and occupation; Water; Teles Pires River; Interview; Report of memory. 


\section{INTRODUÇÃO}

Durante o processo de construção do mundo moderno em que vivemos a racionalidade capitalista foi empregada, e o homem, através de suas ações, tem se apropriado da natureza predatoriamente, intensificando a exploração dos recursos naturais (DICTORO; HANAI, 2016). Dessa forma, a questão ambiental tem se tornado alvo de discussões no âmbito social e científico, assim, a tomada de consciência é o pontapé inicial para a educação ambiental de cada indivíduo da sociedade por meio da percepção ambiental (CUNHA; LEITE, 2009).

Segundo Oliveira e Corona (2008), com a realização de seminários, conferências e congressos que abordam os problemas ambientais e desenvolvimento sustentável é que buscase alertar que os recursos naturais não são infinitos e que a exploração excessiva e o uso inadequado podem trazer sérias consequências para as futuras gerações e por esse motivo a sensibilização da sociedade e a educação ambiental é tão crucial.

Entre estes recursos naturais está a água, elemento importantíssimo para os humanos. Conforme Cabral (2011), todas as atividades humanas estão associadas direta ou indiretamente à água. Assim, a bacia hidrográfica conceituada por Souza et al. (2012) como uma unidade natural cujo limites são criados pelo próprio escoamento superficial das águas ao longo do tempo, resultado da interação da água com outros recursos naturais, como: material de origem, topografia, solo, vegetação e clima, é uma unidade da paisagem primordial para o desenvolvimento das sociedades humanas.

Dictoro e Hanai (2016) argumentam que o conhecimento tradicional de moradores de determinada área de estudo pode ser uma ferramenta importante para subsidiar ações voltadas a conservação e preservação do meio ambiente, da mesma forma que mostra a percepção ambiental da parcela da sociedade envolvida. No entanto, é incipiente as medidas que consideram o conhecimento tradicional para o desenvolvimento de diversas atividades, seja no âmbito do poder público ou privado.

Dessa forma, o conhecimento da história relatada pelos habitantes locais sobre os rios de uma bacia hidrográfica deve ser considerado, pois a água fez e faz parte do desenvolvimento dos moradores. Assim, a água passa a ser uma unidade simbólica para estes e, portanto, os relatos de vivência dessas pessoas são dotados de valor socioambiental e de afetividade (MACHADO, 2003). 
Em síntese, o principal aspecto da percepção ambiental é a identificação da relação entre o homem e o meio ambiente, a maneira como cada ser humano o percebe e o quanto conhece e espera do seu meio, além de como o utiliza e quais são as suas ações culturais voltadas para este meio em que vive (CUNHA; LEITE, 2009). Conforme Tuan (1980), a percepção é resultado dos sentidos aos estímulos ambientais, como também à atividade mental gerada a partir da relação com o ambiente, o que leva o indivíduo a compreender e estabelecer relações com o ambiente.

Visto que a percepção ambiental é um assunto emergente, várias são as pesquisas que abordam essa temática, podendo citar o trabalho de Silva Filho (2010) que estudou a percepção ambiental na bacia hidrográfica do Rio Passauna - Paraná; Andrade, Souza e Leandro (2013) conheceram os diferentes olhares da população sobre a sub-bacia hidrográfica do córrego das Pitas; Dictoro e Hanai (2016) analisaram a percepção ambiental dos moradores da bacia do Rio Mogi-Guaçu por meio da relação homem-água; Teles (2015) usou a percepção ambiental como ferramenta diagnóstica para a integração entre a unidade de conservação e a população do entorno que vivem em comunidade.

Dado o exposto, este trabalho teve como objetivo avaliar a percepção ambiental dos moradores pioneiros da bacia hidrográfica do Rio Tapaiúna, a fim de compreender como ocorreu o processo de ocupação da bacia, bem como a relação afetiva que os moradores possuem com o ambiente em que vivem.

\section{MATERIAIS E MÉTODOS}

\section{Localização geográfica e caracterização ambiental da área de estudo}

A bacia hidrográfica do Rio Tapaiúna localiza-se entre as coordenadas geográficas $10^{\circ}$

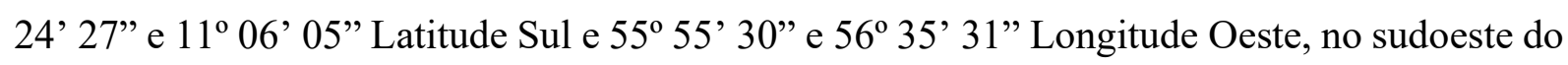
município de Nova Canaã do Norte, na região norte do estado de Mato Grosso (Figura 1). A bacia é contribuinte da margem esquerda do Rio Teles Pires, possui aproximadamente 2.381 $\mathrm{km}^{2}$ e drena propriedades rurais como a Comunidade Tapaiúna e a Comunidade Santa Edvirges.

A temperatura média anual na bacia é de $24,1^{\circ} \mathrm{C}$ a $25^{\circ} \mathrm{C}$ e a distribuição da pluviosidade média anual é de $2.000 \mathrm{~mm}$ a $2.300 \mathrm{~mm}$, com período seco que se estende de maio a setembro e período chuvoso que compreende de novembro a abril. Quanto a geologia da área de estudo destacam-se a Formação Dardanelos (presente no alto e médio curso da bacia), o Complexo 
Xingu (duas estreitas faixas que se estendem na direção NO-SE no médio curso) e as Aluviões Atuais que compreendem o entorno do rio Tapaiúna em seu médio e baixo curso (CAMARGO, 2011).

Figura 1 - Localização da bacia hidrográfica do Rio Tapaiúna

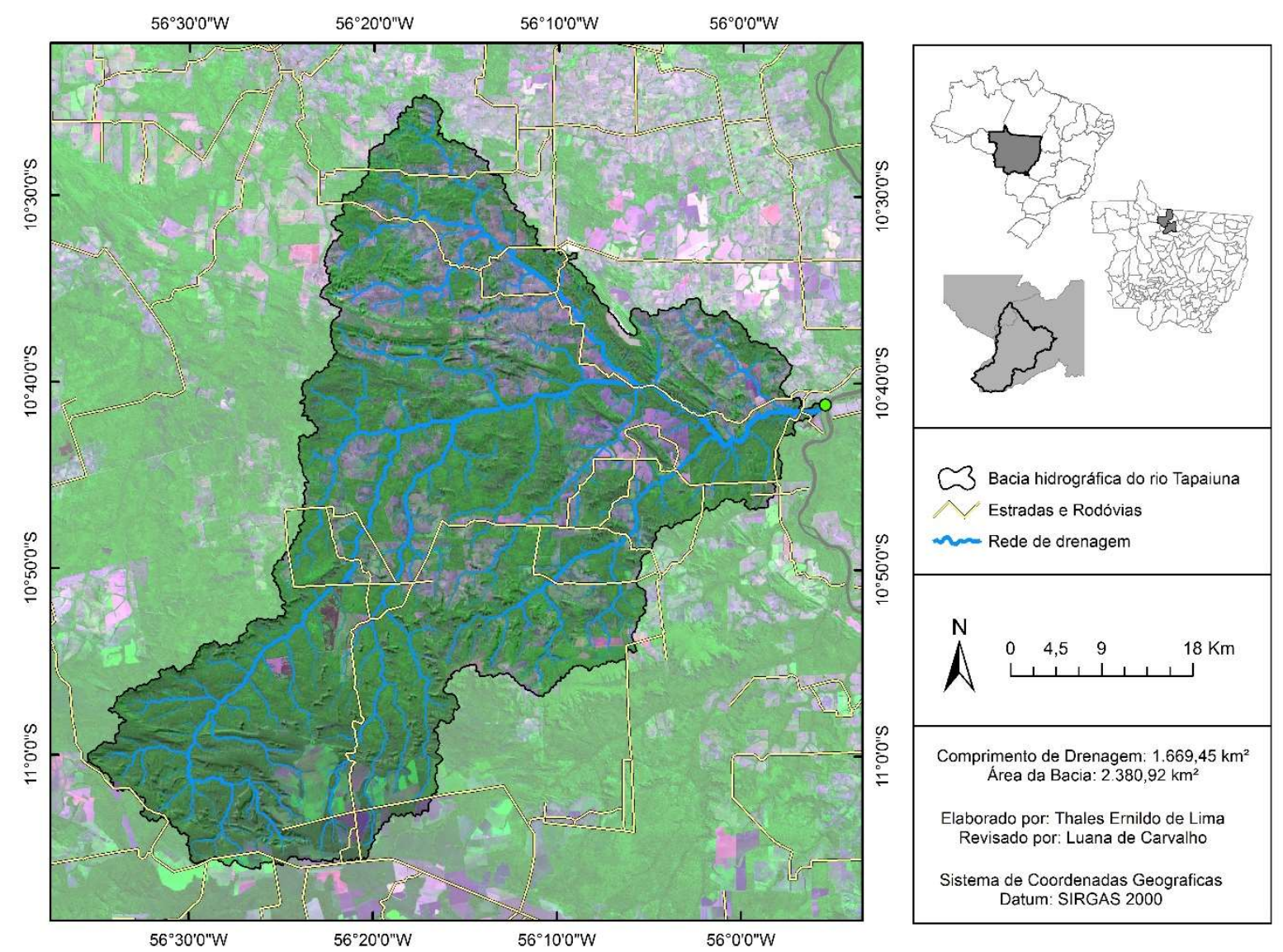

De acordo com o levantamento geomorfológico realizado por Ross (1992 apud CAMARGO, 2011), o estado de Mato Grosso compreende unidades morfoestruturais (macroformas originadas pela atuação das forças endógenas), enquadradas no primeiro táxon do relevo e, unidades morfoesculturais (formadas pela ação das forças exógenas), classificadas no segundo táxon entre os seis níveis hierárquicos taxinômicos do relevo.

Nessa concepção, as morfoestruturas com destaque na bacia hidrográfica são as Coberturas Sedimentares da Plataforma Amazônica e a morfoestrutura da Plataforma Amazônica. As morfoesculturas encontradas na área de abrangência da bacia são: Chapada dos Parecis e Serra dos Caiabis (alto e médio curso da bacia) e a Depressão do Norte Matogrossense (baixo curso).

$\mathrm{Na}$ bacia do Rio Tapaiúna destacam-se as seguintes classes de solos: Latossolo Concrecionário Distrófico (nas imediações da nascente do rio Tapaiúna), Neossolo 
Quartzarênico Distrófico (baixo curso) e Argissolo Vermelho-Amarelo Distrófico (maior abrangência da bacia, estendendo desde o alto ao baixo curso). Em termos de vegetação a área de estudo está situada em uma zona de Tensão Ecológica. Segundo Camargo (2011) essa zona se estende entre os paralelos $10^{\circ} 00^{\prime}$ e $14^{\circ} 00^{\prime}$ Latitude Sul e é caracterizada pelo o contato entre os dois Domínios, o Amazônico e dos Cerrados, sendo a Floresta Estacional/Savana e a Floresta Ombrófila/Floresta Estacional exemplos de tipologias de contato presentes na abrangência da bacia.

A bacia do Rio Tapaiúna constitui a área mais preservadas do território municipal de Nova Canaã do Norte, visto que o processo de colonização e ocupação procedeu primeiramente na porção leste, a partir do ano de 1976, e posteriormente avançou para o "outro lado do rio". O termo local é usado para determinar as áreas à oeste do Rio Teles Pires, e a bacia do Rio Tapaiúna abrange grande parte desse vasto território do município.

O baixo curso da bacia é o segmento que compõe as áreas mais antropizadas, com pastagem e agricultura. Em vista disso, ressalta-se a importância da bacia hidrográfica para a população local e a relevância da preservação dessa unidade ambiental.

Dessa forma, para a realização desta pesquisa, selecionou-se o baixo curso da bacia hidrográfica do Rio Tapaiúna para a aplicação de entrevistas com moradores antigos desta porção da bacia, visto que este segmento foi o primeiro a ser ocupado e, hoje, constitui a comunidade com o mesmo nome da bacia, a comunidade Tapaiúna.

\section{Procedimentos metodológicos}

A abordagem qualitativa é essencial na Geografia referente aos estudos de áreas rurais. Tal abordagem baseia-se na compreensão e interpretação dos fenômenos partindo das suas representações, percepções, valores e crenças. Há, portanto, uma relação dinâmica entre o pesquisador e os sujeitos da pesquisa (SILVA; MENDES, 2013).

Chizzotti (2003) destaca esses desafios da abordagem qualitativa. Para ele, existem questões que provocam os pesquisadores, de ordem epistemológicas e ético-políticas como a solidariedade e participação na transformação deliberada da vida humana. Trata-se, portanto, da consciência e do compromisso de que a pesquisa é uma prática válida e necessária na construção solidária da vida social. Pesquisadores que optam pela pesquisa qualitativa reconhecem que a experiência humana é complexa, ou seja, preocupa-se com o processo e não 
simplesmente com o resultado, tendo o ambiente natural como fonte direta dos dados. Além disso, há relevo à interpretação dos significados das ações sociais (CHIZZOTTI, 2003).

Segundo Brito Júnior e Feres Júnior (2011), para a investigação científica é indispensável que três etapas sejam alcançadas: levantamento bibliográfico; observação dos fatos para deter maiores informações; e coleta de dados que não seriam possíveis somente através da pesquisa bibliográfica e da observação, podendo proceder, portanto, através da técnica da entrevista. Assim, o instrumento usado para a análise da percepção ambiental dos moradores pioneiros da bacia do Rio Tapaiúna foi a aplicação de um questionário por meio de entrevistas.

O modelo de entrevista adotado foi a "semiestruturada", guiada por um roteiro previamente elaborado com questões abertas (MANZINI, 2004). Para a aplicação das entrevistas foram selecionados pioneiros que acompanharam, participaram e vivenciaram e/ou vivenciam o processo de ocupação e uso da terra da bacia hidrográfica do Rio Tapaiúna, com o intuído de compreender a relação de afetividade desses moradores quanto a área de estudo. A escolha de dez pioneiros procedeu por meio de indicação dos próprios moradores da comunidade Tapaiúna. Os moradores foram abordados em suas próprias residências durante a atividade de campo realizada no mês de novembro de 2017.

As entrevistas seguiram um formulário com questões pré-definidas, contendo perguntas sobre o conhecimento dos pioneiros em relação à bacia. Cada entrevista durou em média 15 minutos e, com a permissão da pessoa entrevistada, foi gravada com o auxílio de um gravador de voz, a fim de facilitar a transcrição subsequente.

O questionário foi composto por questões objetivas referentes ao quadro descritivo dos entrevistados (idade, sexo, escolaridade, tempo de conhecimento da região) e as demais questões foram abertas, sendo: Como você conheceu a região do Tapaiúna? Como era a paisagem quando você conheceu? Mudou algum aspecto? Como foi o processo de ocupação da bacia do Rio Tapaiúna? Qual a importância do Rio Tapaiúna para você? Qual proposta você dá para evitar a degradação da bacia hidrográfica do Rio Tapaiúna?

O questionário foi composto por questões objetivas referentes ao quadro descritivo dos entrevistados (idade, sexo, escolaridade, tempo de conhecimento da região) e as demais questões foram abertas, sendo: Como você conheceu a região do Tapaiúna? Como era a paisagem quando você conheceu? Mudou algum aspecto? Como foi o processo de ocupação da 
bacia do Rio Tapaiúna? Qual a importância do Rio Tapaiúna para você? Qual proposta você dá para evitar a degradação da bacia hidrográfica do Rio Tapaiúna?

Duarte (2004) enfatiza que as entrevistas devem ser transcritas logo depois de encerradas, e posteriormente devem passar pela conferência de fidedignidade, que consiste em ouvir a gravação observando o texto transcrito a fim de corrigir possíveis erros. Vale ressaltar que na transcrição não houve edição das falas dos entrevistados, foram mantidos os vocabulários e gírias locais usados, com a pretensão de fazer a análise do discurso.

Após a conclusão das etapas de elaboração do questionário, aplicação de entrevistas e transcrição das falas, foi adotada a análise do discurso para dar consistência à discussão dos dados obtidos por meio das entrevistas. A análise do discurso enfoca o sentido e não o conteúdo do texto, nessa abordagem, Caregnato e Mutti (2006) ressaltam:

\footnotetext{
"Não há sentido sem interpretação", portanto deverá sempre existir uma interpretação para dar visibilidade ao sentido que o sujeito pretendeu transmitir no seu discurso. $\mathrm{Na}$ interpretação é importante lembrar que o analista é um intérprete, que faz uma leitura também discursiva influenciada pelo seu afeto, sua posição, suas crenças, suas experiências e vivências; portanto, a interpretação nunca será absoluta e única, pois também produzirá seu sentido (CAREGNATO; MUTTI, 2006).
}

A interpretação por meio da análise do discurso nesta pesquisa ocorreu com uma leitura aguçada das respostas obtidas em cada entrevista, enfatizando a articulação entre o linguístico e o sócio-histórico dos entrevistados, produzindo sentidos.

\section{RESULTADOS E DISCUSSÃO}

Todos os entrevistados possuiam acima de 45 anos de idade e afirmaram conhecer e residir na região do Tapaiúna por mais de 30 anos, portanto, são pioneiros locais. Das dez pessoas entrevistadas, seis são do sexo masculino e quatro do feminino.

Quanto ao nível de instrução, seis possuiam o $1^{\circ}$ grau incompleto, dois entrevistados tinham o $1^{\mathrm{o}}$ grau completo, uma pessoa com o $2^{\circ}$ grau completo e uma analfabeta.

As 10 entrevistas realizadas com moradores antigos e conhecedores da região serviu para discutir e conhecer a afetividade destes com o ambiente e como procedeu o processo de ocupação da área da bacia hidrográfica de acordo com o ponto de vista dos entrevistados.

De acordo com os entrevistados, o processo de ocupação da área iniciou-se na década de 1980 e através de seus relatos de memória foi possível compreender os primeiros passos para desbravamento da área. 
Quando nós chegamos era tudo mato, né? aí fomos abrindo estrada, derrubando, daí as pessoas foram vindo atrás, porque quando passa o primeiro que faz a estrada já vem outro atrás [...]. E assim a gente foi entrando, foi desmatando, foi fazendo pasto, não tinha estrada, a gente vinha só de barco [...].

Não tinha estrada era só pelo rio, pegava o barco lá na balsa e subia até aqui na barra do Tapaiúna, era nosso meio de transporte, eu cheguei a carregar muito gado no barco, não cabia, não tinha jeito, amarrava a bezerra no ferro do braço e trazia, hoje a gente fala pros outros e falam que é conversa fiada, ninguém acredita.

Em 86, nós andávamos a metade da estrada era mato, metade era derrubado, tinha a balsa, a balsa era pequena, era difícil, chegava na balsa e tinha que ficar esperando carro pra poder passar.

Dado o exposto, foi possível compreender as dificuldades que os pioneiros encontraram durante o processo inicial de ocupação do baixo curso da bacia do rio Tapaiúna. Os mesmos utilizavam barcos como meio de transporte e era através o rio Teles Pires que conseguiam acesso até o rio Tapaiúna, e foi desta forma até que as estradas foram feitas, facilitando a locomoção até a bacia via terrestre. Além disso, foi pontuado a existência de exuberantes florestas e essa vegetação foi gradualmente sendo desmatada para a abertura de estradas e para o uso por pastagem.

Quando foi perguntado sobre os tipos de produção desde o período de colonização até os dias atuais os entrevistados falaram sobre a influência e importância da pecuária para os sitiantes, como também enfatizaram a gradativa mudança para a agricultura, prática fomentada e desenvolvida pelos proprietários de grandes porções de terra.

Viemos pra cá pra plantar café, a gente plantou café depois de cinco anos sofrendo com café agora vamos cortar café, não dava, não prestava, não funcionava. O clima nunca foi pra café, na hora que ele flore tá na seca e não segura carga, se segura é pouco, um dava outro ano não dava e aí dava era prejuízo, trabalhar de graça, um ano não recebe nada, no outro recebe um pouquinho. Quando nós descobrimos que o negócio aqui era gado e até hoje continua sendo gado, aí começamos mexer com gado.

Começaram a plantar lavoura agora, mas a maioria do povo aqui tem pecuária até hoje desde quando começou. Pelo o que eu vejo essas lavouras vão avançar, mas eu não vejo futuro pra essas plantações.

Primeiro foi derrubando, plantando capim para criar gado. Hoje as terras degradaram, e as pessoas estão entrando com agricultura, reformando e plantando lavoura [...]. Hoje nós temos na nossa região uns $30 \%$ de agricultura. Está mudando pra agricultura.

Pra quem tem sitio grande, fazenda, estão mexendo com lavoura, nós não temos como mexer com lavoura, é mais o leite, agora pra quem tem mais terra... 
Por meio dos relatos dos entrevistados, em consonância com os dados do IBGE, sobre o histórico da produção pecuária e agrícola do município, é possível afirmar que a produção agrícola por lavouras temporárias se destacou no município nos últimos anos (Figura 2), enquanto na pecuária, o número efetivo de rebanho bovino diminuiu no mesmo ano (2016) quando a lavoura temporária de soja registrou em salto (Figura 3).

Figura 2 - Produção Agrícola em Nova Canaã do Norte/MT - Lavoura Temporária

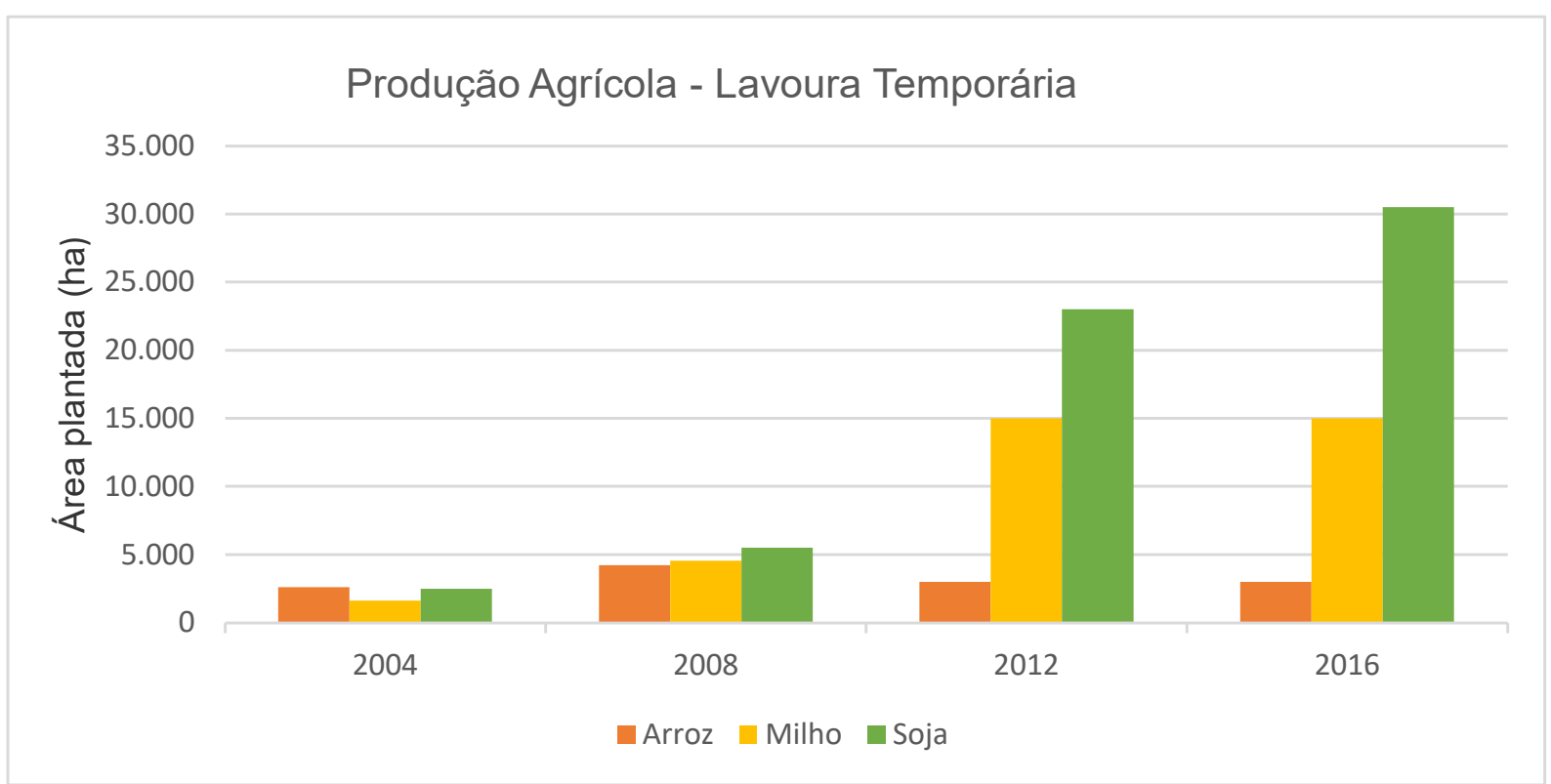

Fonte: IBGE, 2017. Org.: os autores (2017).

Também é perceptível o decréscimo do efetivo rebanho galináceo e suíno no município de 2004 a 2016. Em 2004, o rebanho bovino apresentou o número de 392.884 mil cabeças, em 2012 esse número aumentou para 424.617 mil cabeças (o maior número registrado), mas em 2016 esse número diminuiu para 400.598 mil (Figura 3).

$\mathrm{Na}$ agricultura, lavouras temporárias são as que se destacam economicamente, com ênfase na produção de soja, milho e arroz. As culturas tradicionais que fomentaram a colonização e o desenvolvimento econômico no município nas décadas de 1970 e 1980 estão, paulatinamente, perdendo espaço para soja e o milho (GRANDE..., 2014). A soja, no entanto, acompanhou as tendências de crescimento no cenário agrícola de Mato Grosso, sendo o principal produto entre as lavouras temporárias (PADILHA, 2017). 
Figura 3 - Pecuária em Nova Canaã do Norte/MT

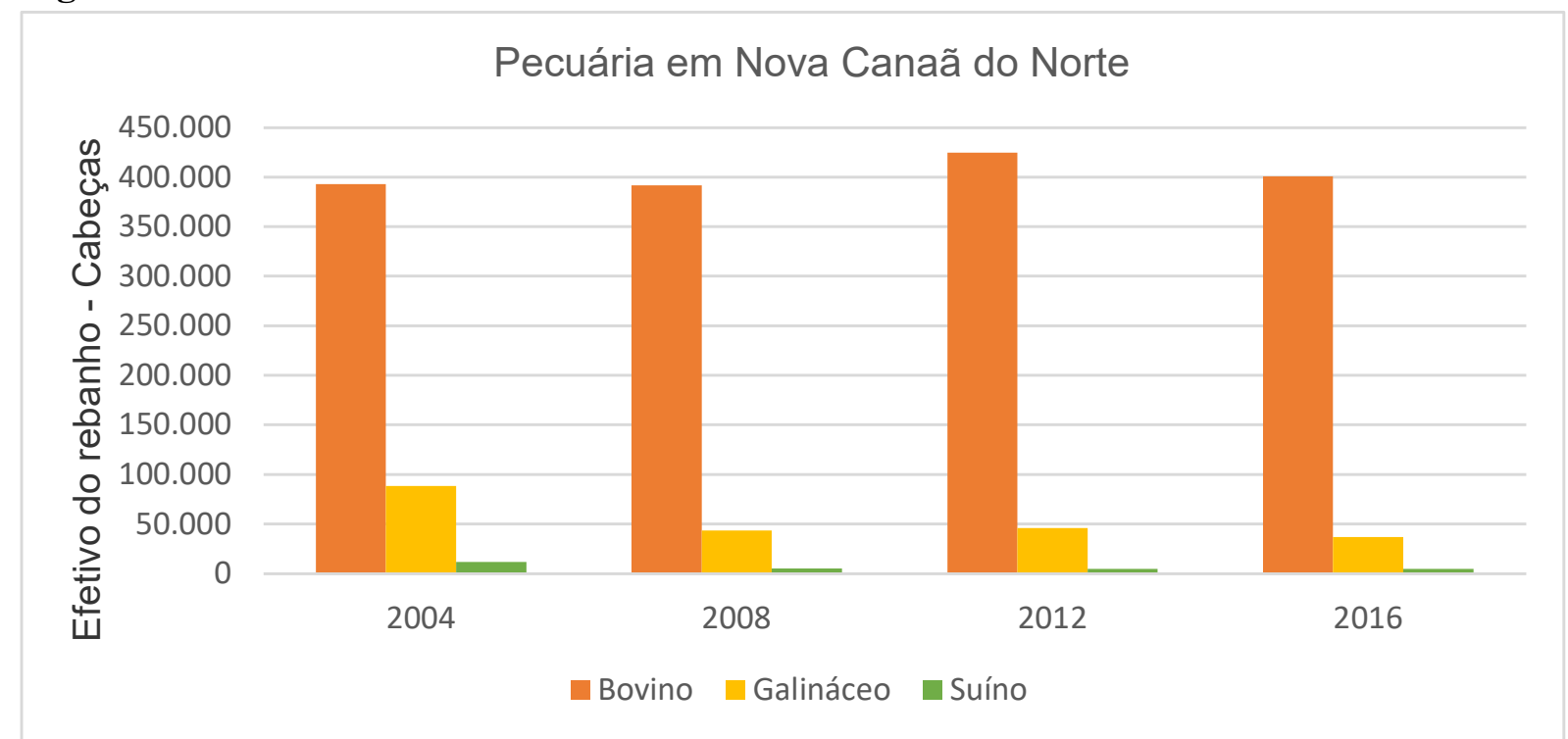

Fonte: IBGE, 2017. Org.: os autores (2017).

Estimativas indicam que os produtores de médias e grandes propriedades rurais estão direcionando seus olhos para a produção agrícola no território canaense, enquanto que a pecuária continua sendo a principal forma de produção em pequenas propriedades, como alegaram os entrevistados.

Diante do exposto, fica nítido que, desde o início do processo de ocupação até os dias mais recentes, a paisagem da bacia foi moldada de acordo com os interesses relacionados aos tipos de usos dessas terras, seja pela pecuária ou agricultura.

Segundo relatos dos entrevistados, a paisagem na região do Tapaiúna pode ser diferenciada pelo porte das árvores e também pelo espaço/tempo, afirmaram que a paisagem no passado era totalmente diferente da atual, tanto na flora quanto na fauna. É possível notar também a preocupação com a preservação das matas e rios.

Do outro lado do Tapaiúna é uma grande área de cerrado, aqui a mata é mais alta. Do outro lado Tapaiúna vamos falar aí que tem uns $70 \%$ ou $60 \%$ de cerrado.

A paisagem mudou uns $80 \%$, antes era tudo mato [...].

Em visto do que era antes para o que é hoje até peixe está faltando aí já, né? Está faltando consciência do povo demais.

A região mudou muito, bastante. Era bem diferente, né? hoje é mais aberto. Quando nós morávamos aqui mesmo era só a casa de tabuinhas, e os matos chegavam beirando assim, era só o círculo da casa, uns pés de frutas. Depois o desmatamento foi liberado, aí foi abrindo. 
Quando questionados sobre a importância do rio Tapaiúna para os entrevistados que se beneficiam esta unidade, percebe-se que eles têm a consciência e a preocupação de cuidar e preservar, inclusive, os rios chegam a ser comparados ao sangue humano devido à preciosidade de suas águas.

A região aqui é conhecida como Tapaiúna por causa da água, por causa do rio Tapaiúna, isso quer dizer que ele tem grande valor, grande significado. Quando você passou da entrada lá que vai pro 12 e vem pra cá, ali na entrada já se identifica como Tapaiúna.

O rio pra nós é tudo, a maior maravilha que nós temos na região é o Teles Pires e o Tapaiúna.

É necessário um ser humano desfrutar da beira do rio, esfria cabeça, é um lugar bonito, ajuda na mente da pessoa, parece que até sara quando está na beira do rio, deixa de ter os problemas.

O homem faz cerveja, faz gasolina, óleo diesel, faz coca, faz tudo quanto é tipo de líquido, mas a água do Tapaiúna ele não faz. Então por que ele não é valioso? Cerveja qualquer um faz e qualquer outra bebida, mas a água só um faz, só Deus.

O rio é igual o sangue que corre dentro da gente, se barrar o nosso sangue a gente morre, se a gente deixar entupir o rio a gente vai ficar sem água, e se ficar sem água, alguém vive?

Por meio desses relatos foi possível perceber a relação de respeito que os pioneiros têm com o Rio Tapaiúna, com suas águas e com o rio Teles Pires, tal fato é de extrema relevância, pois quando nota-se esse respeito e essa percepção da importância do rio para a vida dessas pessoas, dificilmente irão contribuir com a degradação, mas sim buscar formas de proteger, cuidar e preservar.

Notou-se que o Rio possui um forte valor socioambiental para esses moradores, a água ganha sentidos poéticos quando comparada ao sangue que circula nas veias humanas e também um significado simbólico divino, quando retratada como algo proveniente de Deus. Nessa perspectiva, tanto o Rio como a água são essenciais na vida dos entrevistados, seja referente ao uso ou quanto aos significados simbólicos de respeito, pertencimento, identidade, sentimento, religiosidade e saúde.

No transcorrer das entrevistas, os entrevistados mencionaram sobre a importância da preservar a vegetação nativa, matas ciliares e nascentes. Observou-se também a preocupação 
com a erosão marginal que ocorre devido à falta de matas ciliares, causando o assoreamento dos rios.

\begin{abstract}
Aqui tem 60 alqueires de mata, está preservado, não deixo ninguém caçar e pescar aqui. Os córregos, as nascentes estão tudo cheio de mato, essas nascentes aí são de 30 anos atrás que a gente deixou as matas com a consciência mesmo que era de preservar a água, até a turma do Ibama passou e elogiou aqui. Enquanto eu estiver vivo não vou deixar mexer de jeito nenhum, nem eu, nem meus filhos, nem ninguém, quero preservar pro resto da vida, tem onça, tem tudo aí.
\end{abstract}

\begin{abstract}
Quando cheguei aqui sem conhecimento, sem entendimento, nós derrubamos a beira do rio ai passou algum tempo e um dia veio um cunhado meu conversando e falou que na beira do rio a gente não pode derrubar porque pode desbarrancar, nós deixamos algumas árvores na beira do rio, agora está reformando tudo aí, ninguém mexe mais e nem derruba, mais pra refazer vai levar tempo, porque já tem 20 anos e não refez grandes coisa, mais se eu tenho o conhecimento que eu tenho hoje não tinha derrubado isso daí de jeito nenhum, da dó ver a beira do rio que você derrubou agora desbarrancou um pedaço aqui, mais como já tá cheio de árvore de novo, vai parar essa degradação.
\end{abstract}

Eu gosto dos dois rios, inclusive eu já cerquei meus rios tudinho, para o meu gado não ir beber água no rio e estragar, porque a gente sabe que vai aterrando, eu fico com dó quando eu vejo gente até hoje que deixa o gado ir beber água no rio, vai colocando areia dentro do rio. [...]. Quem tem pasto que o gado bebe na beira do rio, deveria cercar pro gado não ir fazer valetas na beira do rio, porque é uma coisa que no momento hoje nós não consegue ver os danos, quem vai ver é nosso bisnetos, vão ver o rio entupido.

Se não tiver a preservação das matas envolta dos rios não vai ter rio no futuro. $\mathrm{O}$ rio tem que ser preservado isso independente de qualquer coisa.

Com esses relatos percebe-se ainda mais consistente a relação de respeito, afetividade e preocupação dos moradores da bacia com o Rio e suas matas ciliares, o que faz do Rio um dos protagonistas da história de vida de cada entrevistado, pois ao longo de grande parte de suas vidas eles tiveram e ainda possuem contato com o Rio.

$\mathrm{O}$ fato de querer manter as nascentes e os rios cercados de matas, cercar o entorno do rio para impedir que o gado tenha acesso e acentue a erosão marginal e o assoreamento do rio, bem como o sentimento de arrependimento de ter derrubado as matas ciliares no passado devido à falta de instrução, reforçam a percepção ambiental e o grau de afetividade que os pioneiros têm sobre os rios.

Notou-se que há a consciência de que o Rio Tapaiúna é um sistema fluvial dinâmico. Foi relatado, em senso comum, o processo de corte de colo de meandro e também sobre a existência de lagoas e baías que, para a pessoa entrevistada, são indicadores dos pretéritos percursos do rio. 
O rio cortou uma ilha ali por motivo de muita água, dava uma volta e ficou muito estreito o lugar que ele dava a volta e cortou, aonde ele cortou que ele desceu com força, aí aqui era mato, nunca foi derrubado, mas por causa dele bater com força foi desbarrancando, é uma mudança natural, ele vai mudando geograficamente por conta, ele faz ilha, ele corta de novo, ele arruma e assim vai, quando eu fui ver, eu conhecia sem a ilha, aí eu fiquei muito tempo sem vir na beira do rio, uns 6 ou 7 anos, quando eu vim já tinha cortado, estava largo, eu admirei [...]. De tempo para tempo muda, é engraçado, a gente vê vazante aí no meio desse mato que possivelmente o rio já passou por lá e já mudou o percurso naturalmente.

Stevaux e Latrubesse (2017) expõem que esse processo de corte de colo de meandro relatado e vivenciado pela pessoa entrevistada ocorre quando os meandros atingem um avançado estágio de migração, onde a sinuosidade do meandro propicia para que as margens se toquem, formando um atalho com maiores proporções hidráulicas. Assim ocorre o processo inicial do abandono do antigo trecho que o rio percorria.

Ao analisar as informações prestadas pelos entrevistados em relação ao rio Tapaiúna, foi possível perceber que ambos concordam sobre a relevância do rio para a região, como também a necessidade de cuidados para o mesmo. Foram significativas as respostas, os relatos convergiram para vivências similares no passado quanto ao processo de ocupação e uso da terra e as atividades desenvolvidas por eles desde antes até a atualidade. Nesse sentido, "pode ser considerado representativo quando várias pessoas concordam com um determinado assunto e não apenas uma pessoa" (FREITAS, 2005 apud SILVA, 2009).

Os entrevistados veem que a degradação da bacia é provocada por todos os envolvidos, tanto a população local quanto aos poderes públicos devido à falta de gerenciamento da bacia. Há, portanto, uma preocupação em recuperar o que foi degradado, pois o rio tem grande relevância para eles. Os entrevistados percebem que o desmatamento e as atividades econômicas sem manejo adequado na região podem causar mudanças no Rio Tapaiúna.

Ao analisar as propostas apresentadas por cada um no final da entrevista, percebeu-se que as questões ambientais estão cada vez mais no cotidiano e na consciência de cada pessoa, mas, assim como foi relatado, o que falta é a sensibilização e a união de todos para diminuir os impactos negativos na área de abrangência do rio Tapaiúna.

Tem que entrar em um bom senso, a tecnologia, quem produz, e os cientistas, os biólogos, pessoal do meio ambiente, todos tem que andar de mãos dadas pra mudar a situação.

Se vai usar não jogue lixo, se vai usar preserva e cuida, né? 
Já tinha que ter tomado providências enquanto é tempo, tem que cuidar. Lei existe, mas as pessoas usam pra benefício próprio.

Tem que juntar o povo, fazer palestras e reuniões.

As pessoas precisam deixar de ser "argola de laço", xucro [...], tem que largar de ser teimoso e se conscientizar.

Nesse aspecto, conforme Montenegro (2000) e Silva (2009), a análise de relatos de memória proporciona a construção de um conjunto de experiências e de ações procedidas no passado pelos autores sociais não seriam possíveis de extrair de outras fontes, como livros e artigos científicos.

Com a realização das entrevistas foi observado o grau de afetividade dos entrevistados quanto aos elementos naturais da bacia hidrográfica do Rio Tapaiúna. Segundo Tuan (1980) o carinho, admiração e instinto de cuidado com a natureza remete-se a topofilia, o elo afetivo entre o indivíduo e o lugar ou meio físico.

Conforme o autor supracitado, o apego à terra do pequeno proprietário rural é profundo, pois os músculos e as cicatrizes testemunham a intimidade física do contado do indivíduo com sua terra. A natureza forma parte dele e ele conhece a natureza porque ganha a vida com ela. O autor reitera que "a topofilia do agricultor está formada desta intimidade física, da dependência material e do fato de que a terra é um repositório de lembranças e mantem a esperança" (TUAN, 1980, p. 111).

A topofilia permeia o emocional com intensidades diversas e isso foi notado com as entrevistas, pois os pioneiros demonstraram apego pelo Rio e pela comunidade Tapaiúna, que se configuram como lar, o qual é muito apreciado e respeitado por representar o passado e suas vivências ao longo de trinta anos.

A partir da percepção dos entrevistados em relação ao Rio Tapaiúna pode-se observar que a vivência, os valores, as relações sociais no processo de ocupação, bem como nas mudanças que ocorreram ao longo da colonização contribuíram com analogias antagônicas que colaboraram com a destruição da paisagem. Os sentimentos vivenciados são importantes para compreender como a população se estabelecia no local e como era a relação entre homem e natureza.

Nessa lógica, as entrevistas proporcionaram a compreensão das relações topofílicas da população com o ambiente em que vivem de maneira a compreender as atitudes errôneas do passado e as que ainda sucedem no presente, como também dos anseios e preocupações voltadas 
à preservação e cuidado das preciosidades e bens comuns de todos os que ali residem, o Rio Tapaiúna, que todos, de certa forma, se beneficiam tanto das águas como dos arredores dos rios.

\section{CONSIDERAÇÕES FINAIS}

As entrevistas realizadas com os pioneiros da região foram essenciais para a pesquisa pois permitiu conhecer a relação dessas pessoas com o ambiente desde o processo de ocupação da região. Notou-se a preocupação da população em preservar o Rio Tapaiúna, a fim de garantir às futuras gerações o uso desse recurso hídrico tão importante para eles.

Pode-se constatar com as entrevistas que as questões ambientais estão presentes no cotidiano e consciência de cada um, porém, segundo os entrevistados, o que falta é a sensibilização e a união de todos visando a mitigação de danos e os impactos negativos futuros. É necessário que todas as camadas da sociedade estejam sensibilizadas quanto a importância da preservação, conservação, recuperação do meio ambiente e desenvolvimento sustentável, no entanto, para alcançar esse feito, é essencial uma boa educação ambiental, que gere o conhecimento verdadeiro sobre os riscos e as consequências do uso indevido dos recursos ambientais.

O conhecimento e a percepção que pioneiros possuem sobre o Rio e a região do Tapaiúna são de suma importância para que ações sejam realizadas visando à gestão da bacia. Estes moradores podem estar à frente de reuniões comunitárias organizadas em parceria com as autoridades públicas municipais e instituições de ensino, com o objetivo de sensibilizar todos os moradores da comunidade por meio de palestras, incentivando ações voltadas à preservação das matas ciliares, ao uso adequado da terra e dos rios e à criação um projeto que contemple o planejamento e o gerenciamento da bacia hidrográfica do rio Tapaiúna.

Desta forma, conhecer a percepção ambiental dos atores da sociedade torna-se o pivô para alcançar o estágio da educação ambiental. Assim, as entrevistas compreendem uma importante ferramenta para conhecimento da percepção ambiental, portanto, crucial para pesquisas de cunho geográfico.

\section{REFERÊNCIAS}

ANDRADE, L. N. P. S.; SOUZA, C. A.; LEANDRO, G. R. S. Sub-bacia hidrográfica do córrego das Pitas - Mato Grosso: diferentes olhares da população araputanguense. Revista Brasileira de Ciências Ambientais, n. 28, p. 52-65, 2013. 
BRITO JÚNIOR, A. F.; FERES JÚNIOR, N. A utilização da técnica da entrevista em trabalhos científicos. Evidência, Araxá, v. 7, n. 7, p. 237-250, 2011.

CABRAL, D. C. Águas passadas: sociedade e natureza no rio de janeiro oitocentista. RA'E GA, Curitiba, v. 23, p. 159-190, 2011.

CAMARGO, L. (org.). Atlas de Mato Grosso: Abordagem socioeconômica - ecológica. Cuiabá: Entrelinhas, 2011.

CAREGNATO, R. C. A.; MUTTI, R. Pesquisa qualitativa: análise de discurso versus análise de conteúdo. Texto Contexto Enferm, Florianópolis, v. 15, n. 4, p. 679-84, 2006.

CHIZZOTTI, A. A pesquisa qualitativa em ciências humanas e sociais: evolução e desafios. Revista Portuguesa de Educação, Braga, v. 16, n. 2, p. 221-36, 2003.

CUNHA, A. S.; LEITE, E. B. Percepção ambiental: implicações para a Educação Ambiental. Sinapse Ambiental, p. 66-79, 2009.

DICTORO, V. P.; HANAI, F. Y. Análise da relação homem-água: a percepção ambiental dos moradores locais de cachoeira de Emas - SP, bacia hidrográfica do rio Mogi-Guaçu. RA'E GA, Curitiba, v. 36, p. 92-120, 2016.

DUARTE, R. Entrevistas em pesquisas qualitativas. Educar, Curitiba, n. 24, p. 213-225, 2004.

GRANDE crescimento na Agricultura de Nova Canaã do Norte. Produção de Prefeitura Nova Canaã, 2014, (01:55 $\mathrm{min}), \quad$ son., color. Disponível em: https://www.youtube.com/watch?v=xCSmcBY4k-U. Acesso em: 04 jan. 2018.

MACHADO, C. J. S. Recursos Hídricos e Cidadania no Brasil: Limites, Alternativas e Desafios. Ambiente \& Sociedade, São Paulo, v. 6, n. 2, p. 121-136, 2003. 
MANZINI, E. J. A entrevista na pesquisa social. Didática, São Paulo, v. 26/27, p. 149-158, 1991.

MONTENEgRO, A. T. O sangue da terra. In: Territórios e Fronteiras. Revista do Programa de Pós-Graduação em História da Universidade Federal de Mato Grosso, v. 1, n. 1, Cuiabá, 2000 .

OLIVEIRA, K. A.; CORONA, H. M. P. A percepção ambiental como ferramenta de propostas educativas e de políticas ambientais. ANAP Brasil, ano 1, n. 1, p. 53-71, 2008.

PADILHA, R. M. Bacia hidrográfica do rio Carapá, Mato Grosso: caracterização ambiental, uso da terra e dinâmica fluvial. 2017. Dissertação (Mestrado em Geografia) Universidade do Estado de Mato Grosso, Cáceres, 2017.

SILVA FILHO, L. V. Qualidade e percepção ambiental: estudo de caso da bacia hidrográfica do rio Passauna. 2010. Dissertação (Mestrado em Engenharia de Recursos Hídricos e Ambiental) - Universidade Federal do Paraná, Curitiba, 2010.

SILVA, J. M.; MENDES, E. P. P. Abordagem qualitativa e geografia: pesquisa documental, entrevista e observação. In: MARAFON, G. J.; RAMIRES, J. C. de LIMA.; RIBEIRO, M. A.; PESSÔA, V. L. S. (org.). Pesquisa qualitativa em geografia: reflexões teórico-conceituais e aplicadas. Rio de Janeiro: Ed. UERJ, 2013. p. 207-222.

SILVA, L. N. P. Bacia hidrográfica do Córrego das Pitas-MT: dinâmica fluvial e o processo de Ocupação, como proposta de gestão dos recursos hídricos. 2009. Dissertação (Mestrado em Ciências Ambientais) - Universidade do Estado de Mato Grosso, Cáceres, 2009.

SOUZA, C. A.; RITELA, A.; PERETTO, A.; SOUSA, J. B.; ANDRADE, L. N. P. S.; SOUZA, M. A.; ARAÚJO, R. M.; MEIRELES, W. S.; SANTOS, Z. G. Bacia Hidrográfica do Rio Jauru e Seus Afluentes. In: SOUZA, C. A.; SOUZA, J. B.; ANDRADE, L. N. P. S. (org.). Bacia Hidrográfica do Rio Jauru - Mato Grosso: Dinâmica espacial e impactos associados. São Carlos: RiMa Editora, 2012. p. 01-28. 
STEVAUX, J. C.; LATRUBESSE, E. M. Dinâmica de ajuste do canal. In: STEVAUX, J. C.; LATRUBESSE, E. M. Geomorfologia fluvial. São Paulo: Oficina de Textos, 2017. p. 155196.

TELES, P. A. Percepção ambiental como ferramenta diagnóstica para o processo de integração entre uma unidade de conservação e a comunidade do entorno. 2015. Dissertação (Mestrado em Ecologia e Conservação de Recursos Naturais) - Universidade Federal de Uberlândia, Uberlândia, 2015.

TUAN, Y. F. Topofilia: um estudo da percepção, atitudes e valores do meio ambiente. São Paulo: DIFEL, 1980. 